\title{
Unusual cause of urinary retention in a child: inflammatory pseudotumor of the urinary bladder
}

\author{
Aakanksha Agarwal ${ }^{1}$, Poonam Sherwani ${ }^{1 *}$ (D, Saurya ${ }^{1}$, Niladri Sekhar Bhunia ${ }^{2}$ and Dipesh Kumar Dhoot ${ }^{3}$
}

\begin{abstract}
Background: Urinary bladder masses are uncommon in the pediatric age group and pose a diagnostic challenge, often necessitating histopathological differentiation and confirmation. An unusual mimic of neoplastic bladder mass is inflammatory pseudotumor, and timely identification and diagnosis of which prevents undue patient stress and radical treatment.
\end{abstract}

Case presentation: We present a case of a 7-year-old female child who presented with hematuria, and a urinary bladder mass was detected on ultrasound which was further characterized by magnetic resonance imaging (MRI) and diagnosed as an inflammatory pseudotumor (IPT) on histopathology.

Conclusions: This case report describes the imaging features of IPT along with a list of differential diagnoses emphasizing the need for radiologists to be aware of this surprising and rare entity.

Keywords: Inflammatory pseudotumor, Hematuria, Histopathology, Pediatric, Case report

\section{Background}

Urinary bladder masses tend to be uncommon in children and have a different list of differential diagnoses as compared to their adult counterparts. Rhabdomyosarcoma tends to be the commonest bladder mass in the first two decades of life while urothelial neoplasms are commoner in the later age [1]. An uncommon entity is an inflammatory pseudotumor (IPT), a mesenchymal bladder mass that tends to occur more frequently in young adult females as compared to the pediatric age group [2].

Clinical manifestations of IPT may range from gross hematuria and anemia to non-specific symptoms like increased urinary frequency, dysuria, and lower abdominal pain [3]. A bladder mass may be identified incidentally on a routine abdominal ultrasound while investigating for urological symptoms. Cross-sectional imaging either

\footnotetext{
* Correspondence: sherwanipoonam@gmail.com

${ }^{1}$ Department of Radiodiagnosis, All India Institute of Medical Sciences, Rishikesh 249203, India

Full list of author information is available at the end of the article
}

CT or MRI may be done to characterize and to look for the extent and associated lymphadenopathy [4]. Considering the "image gently" principles, MRI may be the preferred modality, especially in children as it has double benefits, being non-ionizing and allowing better soft tissue characterization.

\section{Case presentation}

A 7-year-old female presented to the urology department with complaints of decreased urine output and fever for a week. She was a known case of infrequently relapsing, minimal change disease type of nephrotic syndrome and belonged to a lower middle-class family with one disease-free sibling. On presentation, she was having retention of urine due to which she was catheterized following which she had an episode of hematuria. Blood investigations revealed high serum creatinine $(5.46 \mathrm{mg} /$ $\mathrm{dL}$ ), features of azotemia, and acute kidney injury for which she underwent 4 rounds of hemodialysis. Because of raised white blood cell count and continuously raised body temperature in the range of $99-101^{\circ} \mathrm{F}$ which was

\section{Springer Open}

(c) The Author(s). 2021 Open Access This article is licensed under a Creative Commons Attribution 4.0 International License, which permits use, sharing, adaptation, distribution and reproduction in any medium or format, as long as you give appropriate credit to the original author(s) and the source, provide a link to the Creative Commons licence, and indicate if changes were made. The images or other third party material in this article are included in the article's Creative Commons licence, unless indicated otherwise in a credit line to the material. If material is not included in the article's Creative Commons licence and your intended use is not permitted by statutory regulation or exceeds the permitted use, you will need to obtain permission directly from the copyright holder. To view a copy of this licence, visit http://creativecommons.org/licenses/by/4.0/. 
relieved only with medication, she was also started on empirical antibiotics (cefotaxime) for 3 days along with a stress dose of steroids for her nephrotic syndrome.

For her complaints, an abdominal ultrasound was done as the primary investigation which revealed a welldefined polypoidal mass lesion measuring approx. $18 \times$ $18 \times 16 \mathrm{~mm}$ in the region of the neck of the urinary bladder with mild vascularity on color Doppler (Fig. 1).

For further characterization, MRI without contrast was done for the patient due to her poor eGFR and high creatinine. The lesion was well marginated, polypoidal with a hyperintense signal on T2 and hypointense signal on T1. The lesion was involving the neck of the bladder without any local infiltration. There was no significant regional lymphadenopathy and no upstream hydroureteronephrosis. Bilateral kidneys appeared mildly swollen with maintained cortico-medullary differentiation (Fig. 2). Possible radiological differential diagnosis included benign bladder masses which included inflammatory pseudotumor, fibroepithelial polyp, and least likely rhabdomyosarcoma.

Urine routine examination revealed a turbid sample which on microscopy was positive for pus cells, epithelial cells, blood (red blood cells 10-15 cells/high power field), and leukocytes.

Transurethral cystoscopic bladder irrigation was done which showed a polypoidal growth in the bladder neck region with erythematous mucosa. A biopsy was taken which revealed non-specific inflammatory polymorphonuclear neutrophilic leucocytes, histiocytes without myofibroblastic proliferation on hematoxylin and eosin stain.

As the hematuria subsided and there was no significant post-void residual urine, the child was put on conservative management on oral antibiotics (amoxicillin and clavulanic acid) and steroids in the form of prednisolone at $2 \mathrm{mg} / \mathrm{kg}$ for 15 days followed by gradual tapering of steroids and was advised follow-up after 6 weeks. A follow-up ultrasound was performed which revealed more than $50 \%$ reduction in the size of the mass with the residual mass measuring $8 \times 6 \mathrm{~mm}$ (Fig. 3). The patient has been advised to follow up imaging after 2 months or earlier in case of recurrence of symptoms.

\section{Conclusions}

Umiker et al. [5] coined the term inflammatory pseudotumor on account of its resemblance to malignant etiology, both clinically and radiologically. The presence of acute and chronic inflammatory infiltrate with varying degrees of fibrous response characterizes IPT [6]. Fibromyxoid pseudotumor, pseudosarcomatous myofibroblastic tumor, pseudosarcomatous fibromyxoidtumor, nodular fasciitis, and inflammatory myofibroblastic tumor are other names of this entity [7]. Interestingly, IPT has been known to occur anywhere in the body. The most common sites are the lung and orbit urological IPT is very rare [2]. The bladder is the most common site of involvement in urological IPT which has no established causative agent but is seen to develop in response to infection, inflammation, malignancy, or any previous history of surgery in adults. However, in children, the cause is still unknown with no obvious predisposing factors [8]. Hematuria is the most common symptom which is likely due to the vascular nature of the lesion and due to superficial ulceration of the mass. The index case presented with bladder outflow obstruction due to its location, and following catheterization, she had episodes of hematuria which was likely due to bleeding from the mass. These are most commonly seen in females (2:1) [9].

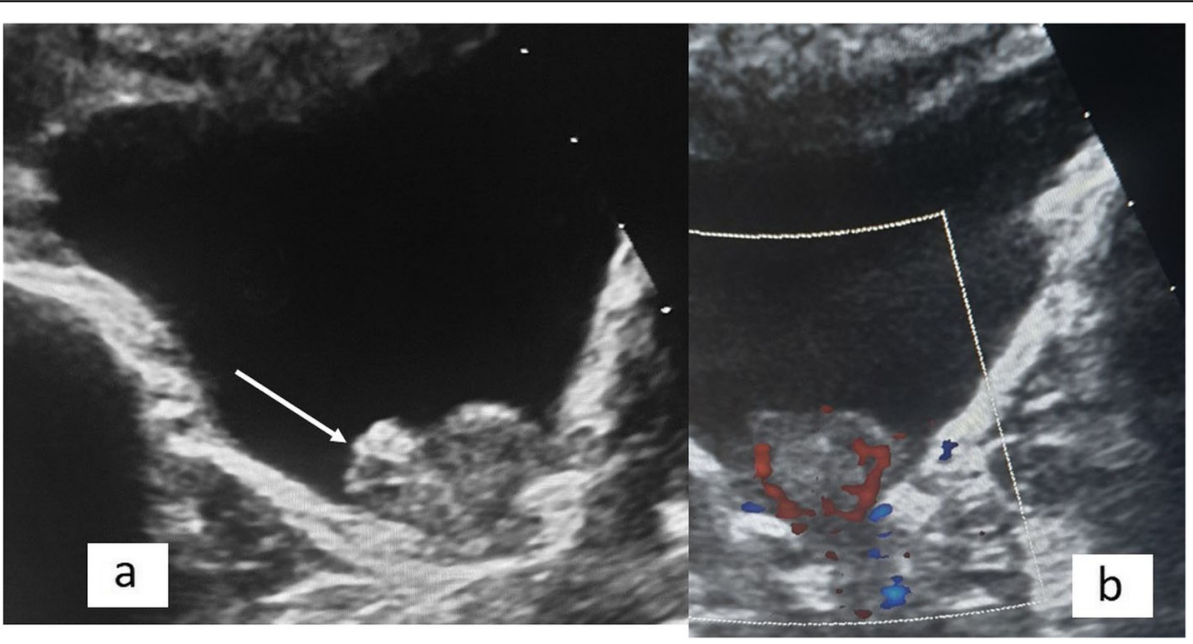

Fig. 1 Transverse grayscale ultrasound (a) and color Doppler (b) image through the pelvis show well-marginated hypoechoic mass lesion (arrow in $\mathbf{a}$ and $\mathbf{b}$ ) arising from the bladder neck projecting into the bladder lumen. The lesion shows mild vascularity 


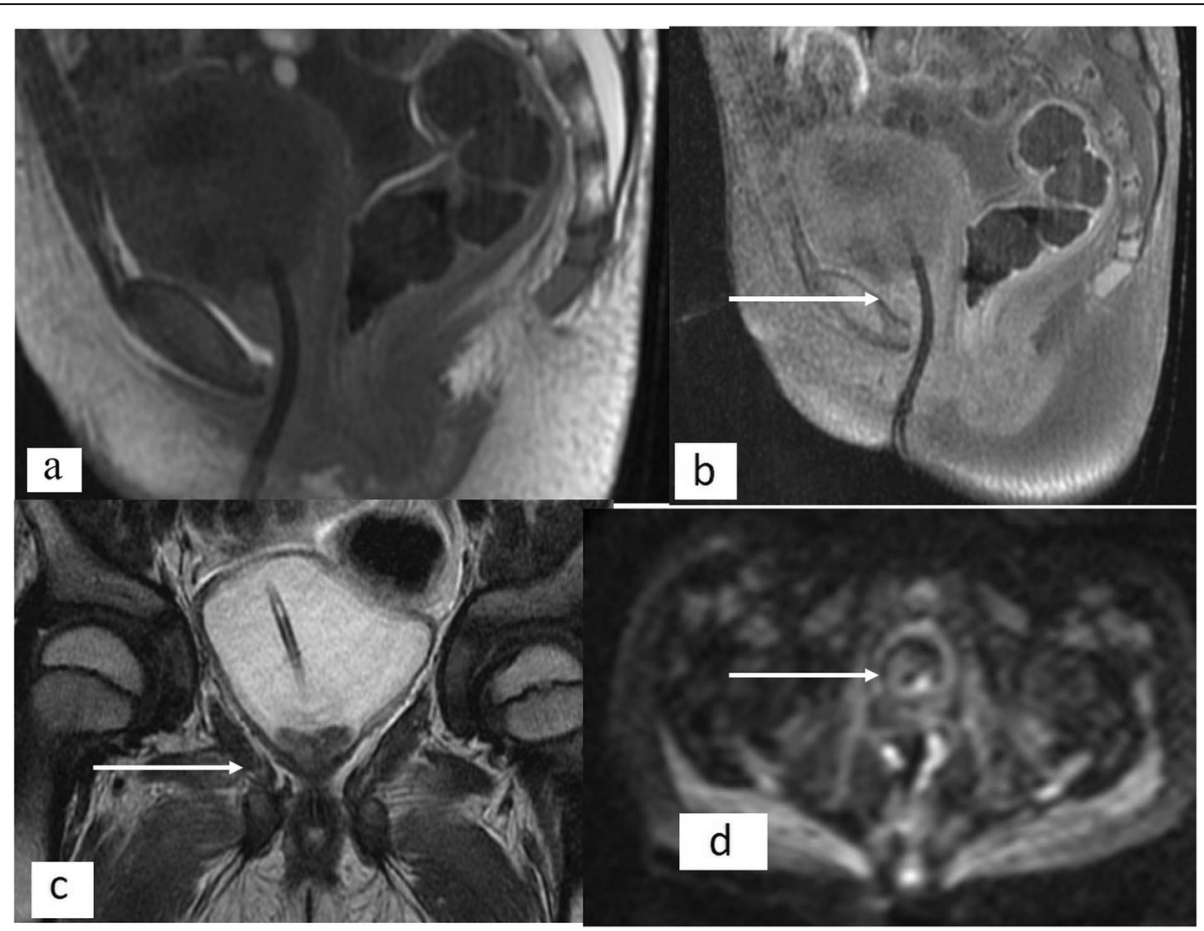

Fig. 2 Sagittal T1W image (a), T2W coronal image (b), and T2W FS axial image through the pelvis show polypoidal lesion arising from the bladder base (arrow in $\mathbf{a}, \mathbf{b}$, and $\mathbf{c}$ ). The lesion is hypo- to isointense on T1W and mildly hyperintense on T2W with no suppression on fatsuppressed images. Patchy areas of diffusion restriction are seen (arrow in $\mathbf{d}$ )

The imaging features are non-specific, varied, and determined by histopathological features of the IPT. On ultrasound, the masses can present as polypoidal outgrowths or as wall thickening, ranging from 1.8 to 13.0 $\mathrm{cm}$ in size. These masses tend to spare the trigone [10]. Internal vascularity is seen on color Doppler predominantly in the peripheral parts of the mass as the central part tends to be necrotic. On CT, the lesions have a heterogeneous appearance showing enhancement on postcontrast scans. The ratio of inflammatory infiltrate, mucin, and cellular component of the lesion will determine its appearance on MR. Mucin predominant lesions will show marked T2 hyperintensity with iso-slight hyperintensity on T1 images. Hypointensity on both T1 and $\mathrm{T} 2$ will be seen in those lesions with abundant collagen. The cellular variety will have a signal intensity intermediate to the above-described varieties, with more evident post-contrast enhancement. IPTs with central necrosis will show peripheral enhancement [11]. Cases similar to ours with raised serum creatinine precluding the use of CT/MRI contrast agents may also be assessed using contrast-enhanced ultrasound which is safe in low eGFR situations. Our patient was unable to afford ultrasound contrast, thus precluding contrast assessment

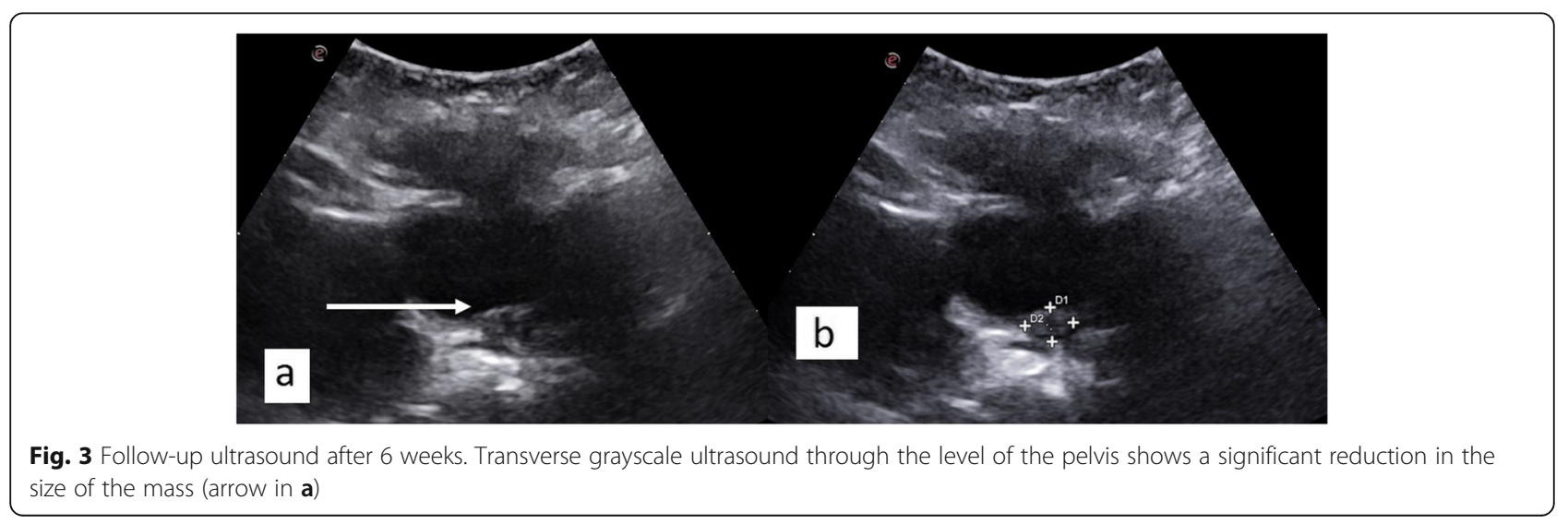


which remains the major limitation of our case report. The signal characteristics on non-contrast MRI corresponded to the cellular variety with mild T2 hyperintensity and $\mathrm{T} 1$ iso-hypointensity.

IPTs may be managed conservatively, by radiotherapy, steroids, or complete excision. In our case, the lesion was causing on and off retention of urine for which she was catheterized. Her symptoms resolved and she was discharged on antibiotics and was put on alternate day steroids for the bladder lesion as well as co-existent nephrotic syndrome.

The major radiological differential diagnoses of urinary bladder IPT in the pediatric age group include rhabdomyosarcoma (RMS), bladder neurofibromas, fibroepithelial polyps, vascular malformations, papillary urothelial neoplasm of low malignant potential (PUNLMP), and rarely urachal remnant cysts [12-15].

RMS tends to be larger, more hypoechoic, homogeneous, obstructing lesions, involving the trigone, contradictory to IPT which tends to spare the trigone [12]. These neoplastic lesions are more infiltrative, having a heterogeneous T2 hyperintense signal. Approximately $63-75 \%$ of bladder neurofibromas that occur before 18 years of age present as a focal mass or diffusely infiltrating bladder mass. Target signs may be seen in plexiform neurofibromas [13]. Vascular malformations may also be seen involving the urinary bladder, more commonly affecting the dome and posterolateral aspects, enhancing avidly with or without intralesional calcifications. Lymph-venous malformations tend to enhance less, maybe polypoidal or diffuse sheet-like on imaging [14]. Papillary urothelial neoplasm of low malignant potential (PUNLMP) is a term added in the 2004 World Health Organization-International Society of Urological Pathology classification which corresponds to grade I urothelial malignancy. These lesions tend to be common in children, occurring in posterolateral walls and described on imaging as "seaweeds in ocean" $[4,15]$. Fibroepithelial polyps tend to occur commonly in males around 9 years of age with non-specific radiological features [4]. Urachal remnant cysts may also be included in the list of differential diagnoses of predominant cystic type of IPTs and can be differentiated by their typical location in the anterosuperior aspect.

This case report emphasizes the need to be aware of benign tumor mimickers in the pediatric population to initiate early management after histopathological confirmation of imaging findings.

Written informed consent was obtained from the patient for publication of this case report and accompanying images.

\section{Abbreviations}

IPT: Inflammatory pseudotumor; CT: Computed tomography; MRI: Magnetic resonance imaging; eGFR: Estimated glomerular filtration rate;

RMS: Rhabdomyosarcoma
Acknowledgements

To the department of pediatrics and urology.

Authors' contributions

PS, NBS, and DKD were the primary consultants for the case. AA and S drafted the manuscript, collected the patient data, and performed the literature search. Finalization of the manuscript was done by PS. All imaging was performed under the guidance of PS. All authors read and approved the final manuscript.

Funding

No funding sources

Availability of data and materials Not applicable.

\section{Declarations}

Ethics approval and consent to participate

The need for approval was waived off by the institute ethical committee.

Consent for publication

Guardian consent has been taken for publication.

\section{Competing interests}

The authors declare that they have no competing interests.

\section{Author details}

1Department of Radiodiagnosis, All India Institute of Medical Sciences, Rishikesh 249203, India. ${ }^{2}$ Department of Pediatrics, All India Institute of Medical Sciences, Rishikesh, India. ${ }^{3}$ Department of Urology, All India Institute of Medical Sciences, Rishikesh, India.

Received: 11 January 2021 Accepted: 19 April 2021

Published online: 14 July 2021

\section{References}

1. Schneider G, Ahlhelm F, Altmeyer K, Aliani S, Remberger K, Schoenhofen H, et al. Rare pseudotumors of the urinary bladder in childhood. Eur Radiol. 2001;11(6):1024-9. https://doi.org/10.1007/s003300000687.

2. Patnana M, Sevrukov AB, Elsayes KM, Viswanathan C, Lubner M, Menias CO. Inflammatory pseudotumor: the great mimicker. Am J Roentgenol. 2012; 198(3):W217-27. https://doi.org/10.2214/AJR.11.7288.

3. Park SB, Cho KS, Kim JK, Lee JH, Jeong AK, Kwon WJ, et al. Inflammatory pseudotumor (myoblastictumor) of the genitourinary tract. Am J Roentgenol. 2008:191(4):1255-62. https://doi.org/10.2214/AJR.07.3663.

4. Shelmerdine SC, Lorenzo AJ, Gupta AA, Chavhan GB. Pearls and pitfalls in diagnosing pediatric urinary bladder masses. Radiographics. 2017;37(6): 1872-91. https://doi.org/10.1148/rg.2017170031

5. Umiker WO, Iverson LC. Post-inflammatory tumor of the lung: report of four cases simulating xanthoma, fibroma or plasma cell granuloma. J Thorac Surg. 1954;28(1):55-62. https://doi.org/10.1016/50096-5588(20)30758-3.

6. Umiker WO. Post-inflammatory "tumors" of the lung. Report of four cases simulating xanthoma, fibroma or plasma cell tumor. J Thorac Surg. 1954; 28(1):55-63. https://doi.org/10.1016/S0096-5588(20)30758-3.

7. Ghonge NP, Mittal D, Jain S, Aggarwal B, Moshiri M, Lall C, et al. Urologic manifestations of inflammatory pseudotumor: report of 2 cases and review of the literature. Radiol Case Rep. 2012;7(3):742. https://doi.org/10.2484/rcr. v7i3.742.

8. Collin M, Charles A, Barker A, Khosa J, Samnakay N. Inflammatory myofibroblastic tumour of the bladder in children: a review. J Pediatr Urol. 2015;11(5):239-45. https://doi.org/10.1016/j.jpurol.2015.03.009.

9. Kumar A, Bhatti SS, Sharma S, Gupta SD, Kumar R. Inflammatory pseudotumor of urinary bladder-a diagnostic and management dilemma. Int Urol Nephrol. 2007;39(3):799-802. https://doi.org/10.1007/s11255-0069113-6.

10. Lecuona AT, Van Wyk AC, Smit SG, Zarrabi AD, Heyns CF. Inflammatory myofibroblastictumor of the bladder in a 3-year-old boy. Urology. 2012; 79(1):215-8. https://doi.org/10.1016/j.urology.2011.04.052. 
11. Sugita R, Saito M, Miura M, Yuda F. Inflammatory pseudotumour of the bladder: CT and MRI findings. Br J Radiol. 1999;72(860):809-11. https://doi. org/10.1259/bjr.72.860.10624350.

12. Harel M, Ferrer FA, Shapiro LH, Makari JH. Future directions in risk stratification and therapy for advanced pediatric genitourinary rhabdomyosarcoma. Urol Oncol. 2016;34(2):103-15 Elsevier.

13. Cheng L, Scheithauer BW, Leibovich BC, Ramnani DM, Cheville JC, Bostwick DG. Neurofibroma of the urinary bladder. Cancer. 1999;86(3):505-13. https:// doi.org/10.1002/(SICI) 1097-0142(19990801)86:3<505:AID-CNCR20>3.0.CO;2-A.

14. Willihnganz-Lawson K, Gordon J, Perkins J, Shnorhavorian M. Genitourinary and perineal vascular anomalies in children: a Seattle children's experience. J Pediatr Urol. 2015;11(4):227-e1.

15. Ball RY. Pathology and genetics of tumours of the urinary system and male genital organs. Histopathology. 2005;46(5):586. https://doi.org/10.1111/j.13 65-2559.2005.02096.x.

\section{Publisher's Note}

Springer Nature remains neutral with regard to jurisdictional claims in published maps and institutional affiliations.

\section{Submit your manuscript to a SpringerOpen ${ }^{\circ}$ journal and benefit from:}

- Convenient online submission

- Rigorous peer review

- Open access: articles freely available online

- High visibility within the field

- Retaining the copyright to your article

Submit your next manuscript at $\boldsymbol{\nabla}$ springeropen.com 